Новицкая Варвара Викторовна

аспирант кафедры социологии коммуникативных систем социологического факультета Московского государственного университета имени М.В. Ломоносова

\section{МАРГИНАЛЬНАЯ КУЛЬТУРА: АНАЛИЗ ФЕНОМЕНА В СОЦИАЛЬНОЙ СТРУКТУРЕ ГОРОДСКОГО ПРОСТРАНСТВА}

Аннотация:

В статье рассматриваются основные определения маргинальности и маргинальной культуры, представленные различными авторами, коллективом авторов и исследовательскими иколами. Трактуется феномен городской среды, ее основных особенностей и характеристик, анализируются специфика городской жизни, жизнь человека в городском сообществе, особенности его самоопределения. Определяются особые признаки городской маргинальной культуры. Выявляются различные процессы и закономерности, влияющие на распространение и развитие маргинальной культуры в жизни общества. Также в статье представлены периоды маргинализации общества, исследуются их основные особенности. Рассматривается «кризис миграции» как особый период маргинализации общества, характерный современному его развитию и вобравший в себя все основные характеристики прошлых периодов данного феномена. Выявляются особенности маргинального процесса в рамках городов.

Ключевые слова:

маргинальная культура, городская маргинальная культура, городская среда, культура, маргинальность, маргинализация общества, субкультура, аккультурация.

\section{Novitskaya Varvara Viktorovna}

PhD student, Sociology of Communicative Systems Subdepartment, Sociology Department,

Lomonosov Moscow State University

MARGINAL CULTURE:

AN ANALYSIS OF THE PHENOMENON IN THE SOCIAL STRUCTURE OF THE URBAN SPACE

Summary:

The research considers the main definitions of margin ality and marginal culture presented by various sociologists, a group of authors and research schools. The urban environment, its main features and characteristics are examined; the urban life, human life in the urban community, and personal self-determination are reviewed. The specific characteristics of an urban marginal culture are analyzed. The study identifies various processes and patterns that affect the distribution and development of marginal culture in the life of society. Besides, the research presents different periods of social marginalization. The migration crisis is regarded as a special period of society's marginalization which is typical for its modern development and includes the main characteristics of past periods of this phenomenon. The peculiarities of the marginal process within the cities are revealed.

Keywords: marginal culture, urban marginal culture, urban environment, culture, marginality, marginalization of society, subculture, acculturation.

Феномен маргинальной культуры возник еще в начале XX столетия, когда часть переселенцев из Старого Света ассимилировалась с населением колоний, в результате чего образовалась группа «этнических гибридов», т. е. маргиналов по этническому происхождению [1]. Наиболее известен «гавайский феномен», который ввели социологи в этот период времени. Он возник на Гавайских островах, где в результате использования американскими колонизаторами рабочей силы из Японии, Китая и Филиппин произошло смешение и слияние различных культур.

В научный обиход термин «маргинальность», «маргинальная культура» ввел американский социолог Р. Парк. В своем эссе «Человеческая миграция и маргинальный человек» ученый отмечает, что маргинальный человек - это человек, деятельность которого сочетает в себе симбиоз традиций и культуры нескольких народов [2]. При этом автор слишком много внимания уделяет культурологическому аспекту проблемы в ущерб социальному процессу аккультурации.

Его последователь, Э. Стоунквист, считал, что маргинальное положение социального субъекта, т. е. его нахождение «между двух огней», вполне способно привести к формированию личности с новыми свойствами [3]. Э. Стоунквист не вдавался в характеристику такой личности пойдет ли появление новой культуры, инакомыслящих людей на пользу состоявшемуся обществу. Человеку, который не может отнести себя к какой-либо из сложившихся в обществе культур и, более того, смешавшему ценности нескольких культур, довольно сложно функционировать, особенно в ритме большого города, где наблюдается высокая степень напряженности в различных сферах жизни. Вероятность отчаяния и проявления маргинальности в таком положении наиболее высока.

Другое определение понятию маргинальной культуры дает в своей «Энциклопедии социологии» М.Р. Жбанков. Определение, представленное автором, выведено из классического определения маргинальности. «Маргинальная культура - совокупность локальных культур (субкуль- 
тур), базисные принципы которых оцениваются с точки зрения господствующего культурного канона как чуждые или враждебные. Социокультурный статус маргинальной культуры определяется их размещением на "окраинах" соответствующих культурных систем, частичным пересечением с каждой из них и лишь частичным признанием с их стороны» [4]. Для понимания вышеуказанного определения необходимо рассмотреть термин «субкультура» в формулировке, данной И.Н. Красавцевой, которая трактовала субкультуру как понятие, характеризующее внутреннюю культуру группы людей, отличную от господствующей в конкретном обществе и зачастую ей враждебную [5]. На наш взгляд, маргинальная культура представляет собой симбиоз некоторых субкультур, которые негативно сказываются на культуре общества в целом. При этом нельзя не отметить сходство между понятиями «субкультура» и «маргинальная культура».

В связи с указанными факторами феномен «маргинальной культуры» рассматривался на протяжении столетия не только и не столько отдельными учеными, сколько целыми социологическими школами. Наиболее известной социологической школой, оставившей значительный след в области маргинальной культуры, является так называемая Франкфуртская школа, представляющая собой критическую теорию современного (индустриального) общества, разновидность неомарксизма [6]. Можно говорить о том, что Франкфуртская школа, в отличие от большинства социологов, наоборот, поддерживала развитие маргинальной культуры. Связано это, на наш взгляд, в первую очередь с критической теорией М. Хоркхаймера, которая гласит, что «субъект и объект - разные стороны некой целостности - тотального праксиса. Разрыв субъекта и объекта консервирует отчуждение» [7]. При этом Хоркхаймер придерживался мнения, что сложившееся общество подвержено господствующей идеологии (т. е. традиционной теории) от элиты до рабочих слоев. Таким образом, единственной естественной средой, где могла распространиться критическая теория, представлялись маргинальные слои.

Иного мнения придерживались последователи Чикагской социологической школы, в том числе и упомянутый выше основатель школы Р. Парк, занимавшийся изучением городской среды. Коллектив исследователей совместно с Р. Парком обнаружил факт разрушения привычных форм коммуникации людей в процессе переезда в большие города и появления «естественных ареалов», где они проживают с людьми, которые близки новым горожанам по своим культурным традициям и обычаям.

Чтобы сорормировать понятие городской маргинальной культуры, выделим характерные черты и признаки явлений маргинальности, культуры и городской среды. Для характеристики городской среды обозначим особенности ее устройства:

- пространственно-территориальное нахождение - обычно это концентрация относительно большого числа людей на сравнительно маленькой площади;

- особенности социально-экономического характера - разнообразие трудовой деятельности, высокая степень дифференциации в социальной и экономической сферах;

- особенности социокультурного характера - наличие динамичности, маргинальности, анонимности городского сообщества.

Город - место, где социальные отношения характеризуются появлением новых форм взаимодействия. Городская жизнь подразумевает смену образцов поведения, преобразование духовных ценностей.

Город отличается своими постоянными изменениями, спадами и ростом эмоционального настроя, стремлениями к жизни в ее идеализированном образе. Именно город является отражением настроения и различных жизненных устоев его жителей. Город может ломать судьбы, строить их, поднимать и опускать человека по социальной лестнице. Зачастую понимание своего «места» в такой структуре зависит от решений и действий самого человека. Социокультурный конфликт - главная характеристика маргинального человека в рамках городского сообщества. Городская среда - среда более сложная и многообразная.

Город - скопление культур, укладов и устоев. Именно в рамках городов происходит развитие и взаимопроникновение национальных культур, соотнесение себя с которыми и самоопределение в условиях городского пространства, где присутствует широкий выбор и возможности, довольно сложно и проблематично. Из этого следует принадлежность маргинального человека нескольким культурам одновременно.

Маргинальность - особый тип взаимоотношения различных культур, который наиболее ярко проявляется в результате различных социальных процессов и изменений в жизни общества. Отечественные ученые (Л.Л. Рыбаковский, Ж.А. Зайончковская, И.Н. Молодикова, О.Д. Воробьева, Г.С. Витковская, В.И. Мукомель) при изучении маргинальной культуры разделяют процессы маргинализации общества на два периода. Первый представляет собой маргинализацию населения в связи с коренными нарушениями социально-политической и классовой структуры общества. Второй - миграционные процессы, связанные с индустриализацией общества. При этом именно миграционные процессы наиболее способствуют развитию маргинальной культуры в современном обществе. Связано это в первую очередь с тем, что именно иммигранты являются наиболее многочис- 
ленной группой маргиналов. Данная многочисленность (например, в России на 2017 год насчитывается около 25 млн мигрантов, при этом около 12,5 млн человек приходится на Москву и МО) [8] объясняется застоем экономики в ближнем зарубежье, а также отсутствием рабочих мест в глубинках самой страны. Это приводит к тому, что территориально-культурная маргинальность умножается еще и на этническую, что благодаря смешанным бракам приводит к этнической эрозии нации и, как следствие, активному развитию маргинальной культуры, угасанию основных моральных ценностей целой нации. Исходя из этого, можно сделать вывод, что на сегодняшний день мы наблюдаем третий период маргинализации общества, который включает в себя основные характеристики прошлых периодов. Условно данный период можно обозначить как «кризис миграции», слишком большое количество представителей иной культуры приезжают в города за лучшей жизнью, слишком много заключается межрасовых браков, слишком много переплетений нескольких культур.

Самая многочисленная группа маргиналов в России - это мигранты. Обычно мигранты стремятся в более крупные и, соответственно, новые для себя города с целью поиска нового места работы, лучшего заработка и более широких возможностей. Но главная проблема, с которой сталкиваются «переселенцы», - сложность принятия новой культуры большого города. Она проявляется в дальнейшем в видоизменении человека на эмоциональном уровне, в особой маргинальности биологического характера, которая выражается в психологической неустойчивости личности, раздвоенности, сложности принятия новых ценностей и идеалов. Тяжелые условия быта и труда выливаются впоследствии в психические заболевания.

Из вышеизложенного может показаться, что миграция - это негативное социальное явление. На самом деле, это не так. С демографической точки зрения феномен «миграция» является абсолютно положительным, так как увеличивает население страны, как за счет мигрантов, так и за счет их будущего потомства. С экономической точки зрения феномен «миграция» также представляется положительным за счет увеличения рабочей силы страны и города. Таким образом, можно предположить, что единственная проблема миграции - это межрасовые браки, соответственно, проблему маргинализации общества можно решить с помощью запрета таких браков. Но это в корне неверное суждение. Говоря о влиянии межрасовых браков на маргинализацию общества, важно помнить, что в социологическом смысле термин «маргинальность» «являет собой неполное принятие той или иной социальной роли, неполное вхождение в состав той или иной социальной группы, социального института» [9]. Следовательно, маргинальность всегда относительна, а значит, ее нельзя ассоциировать с каким-либо социальным институтом, не бедность или безнравственность является причиной маргинальности, а так называемая «недосоциализация».

Термин «недосоциализация» не является научно признанным, но зачастую используется в работах по маргинальной культуре и представляет собой неверное или неполное восприятие и воспроизводство иной культуры. При этом под понятием «культура» традиционно понимают принятую в обществе систему ценностей, моральных норм и правил, признанных этим обществом. Воспроизводство же культуры - это в первую очередь взаимодействие между индивидами.

Для социализации необходимо полное понимание поведения людей в той или иной ситуации, оценка поведения исходя из понимания культуры индивидуума. Таким образом, не так страшен брак между этнически различными представителями общества, как брак между людьми, не имеющими представления о культуре друг друга. При этом такие браки возможны не только между представителями различных национальностей, но даже между представителями единой этнической группы, проживавшими ранее на различных территориях или в различных социальных слоях.

Нежелание или неумение понять привычки, ценности и правила другого человека приводит к тому, что дети, растущие в таких семьях, стараются перенять те черты культуры родителей, которые им ближе, что приводит именно к маргинальности и созданию собственных субкультур, имеющих все признаки маргинальности. Поэтому нет ничего удивительного, что в обстоятельствах имеющегося кризиса культуры наиболее подвержены маргинальности именно представители молодежи. Данный фактор и является наиболее негативным в аспекте феномена «маргинальной культуры» в связи с возникшей в последние десятилетия многочисленностью формирования и самопрезентации различных, по большей степени агрессивно настроенных, групп меньшинств, особенно в структуре больших городов. Имеются в виду не только секс-меньшинства, которые на данный момент не нашли большой поддержки в России, но и различные субкультуры (как, например, относительно недавно возникшее чайлдфри); различные тоталитарные секты, ограничивающие права человека, несущие опасность для общества и государства, а также для жизни и здоровья граждан; новые религиозные движения, обесценивающие нормы морали прошлых поколений; группы этнических меньшинств, создающие резонанс в обществе; сетевые меньшинства (наиболее известная из которых «группа смерти» унесла жизни множества подростков) [10]. При этом стоит отметить, что наибольшее количество таких меньшинств приходится на крупные города, что связано как с высокой плотностью населения, так и с интенсивным информационным и материальным обменом. 
Наибольшее количество вышеперечисленных меньшинств возникло в Европе в силу саморазрушения общества. Следовательно, можно заключить, что основа конфликта между социальными группами кроется не в культурных различиях, а в конфрликтах социального направления: различное положение в обществе, различные социально-экономические связи и отношения, ценностей и моделей поведения, т. е. в самой сущности культуры общества, которая наиболее ярко выражена именно в рамках больших городов.

Городская маргинальная культура характеризуется наличием большого числа различных культур локального характера. Их появление является результатом дифференциации, которая существует в среде городского сообщества. Бедность, безработица, экономическая и социальная нестабильность, несбыточность надежд, крушение планов интенсифицируют процесс маргинализации населения. В результате появляется социальный слой пауперов как следствие усиливающейся нисходящей социальной мобильности, нарастающей по своей интенсивности. Так формируется и укрепляется «социальное дно», которое фактически отторгается обществом, практически не знающим даже его истинных размеров. Данные, полученные в результате исследования, проведенного Институтом социально-экономических проблем народонаселения Российской академии наук, показывают, что нижняя граница размеров «социального дна» составляет 10 \% городского населения, или 10,8 млн человек, в составе которых 3,4 млн человек нищие, 3,3 млн - бомжи, 2,8 млн - беспризорные дети и 1,3 млн человек - уличные проститутки. Указанные цифры не совпадают с официальной статистикой. Так, по данным МВД РФ, бездомных в России от 100 до 350 тысяч [11], и это естественно, потому что правоохранительные органы фиксируют лишь ту часть социального дна, которая попадает в их поле зрения, что не отражает действительность полностью.

Учитывая все перечисленные признаки и специфику маргинальной культуры, необходимо отметить, что это явление особое и целостное, оно неотъемлемая часть жизни городского сообщества, его социальной структуры.

Маргинальность представляет собой пограничное состояние между двумя культурами. Часто она выражается в потере своего социального статуса, который сложно заново обрести в рамках больших городов. Безработица, переосмысление социальных ожиданий и другие факторы выливаются в утрату человеком социальных связей, его моральное расстройство.

Феномен «маргинальной культуры» отличается междисциплинарным характером. Его необходимо изучать не только в социологии, но и во многих других науках, таких как психология и культурология. Рассмотрение указанного феномена возможно при помощи применения научных методов, например метода социокультурных наблюдений или социопсихологических и социокультурных инверсий. Для наиболее полного рассмотрения данного феномена необходимо использовать и эмпирические, и теоретические методы.

Важно отметить, что маргинализация - явление, несущее последствия не только для одной конкретной страны, но и для мирового сообщества в целом. И подходить к решению вопроса необходимо комплексно, разрабатывая определенные программы, способствующие более «легкому» и «безболезненному» включению в процесс принятия новой культуры. Среди практических рекомендаций можно отметить проведение бесплатных экскурсий, встреч с представителями культуры, творческих вечеров, направленных на знакомство с культурой и бытом той страны или города, в среду которого происходит включение новых людей. Процесс самоопределения и аккультурации в новом городском пространстве, таким образом, будет облегчен для новых «переселенцев» в значительной степени. Немаловажными также являются индивидуальные особенности человека: его способности быстро ассимилироваться, находить выходы из стрессовых ситуаций.

\section{Ссылки:}

1. Colyvas J.A., Jonsson S. Ubiquity and Legitimacy: Disentangling Diffusion and Institutionalization // Sociological Theory. 2011. Vol. 29, no. 1. P. 27-53.

2. Park R.E. Human migration and the marginal man // American Journal of Sociology. 1928. Vol. 33, no. 6.

3. Stonequist E.V. The Marginal Man. A Study in personality and culture conflict. N. Y., 1961.

4. Жбанков М.Р. Маргинальная культура // Социология : энциклопедия / сост. А.А. Грицанов, В.Л. Абушенко, Г.М. Евелькин, Г.Н. Соколова, О.В. Терещенко. Минск, 2003. 1312 с.

5. Красавцева И.Н. Субкультура [Электронный ресурс] // Энциклопедия социологии. URL: https://sociology_encyclopedy.academic.ru/1090/СУБКУЛЬТУРА (дата обращения: 09.12.2017)

6. Colyvas J.A., Jonsson S. Op. cit.

7. Хоркхаймер М., Адорно Т.В. Диалектика Просвещения. Философские фрагменты. СПб., 1997.

8. Об актуальных задачах реализации государственной миграционной политики с учетом международной обстановки // Аналитический вестник / под ред. В.Д. Кривовой. 2017. № 55. 79 с.

9. Мигашкина Н.Б. Городская маргинальная культура: понятие и сущность // Муниципалитет: экономика и управление. 2008. № 5.

10. Ионин Л.Г. Восстание меньшинств. М., 2012. 237 с.

11. Кривова В.Д. Указ. соч. 


\section{References:}

Colyvas, JA \& Jonsson, S 2011, 'Ubiquity and Legitimacy: Disentangling Diffusion and Institutionalization', Sociological Theory, vol. 29, no. 1, pp. 27-53. https://doi.org/10.1111/j.1467-9558.2010.01386.x.

Horkheimer, M \& Adorno, TW 1997, Dialectic of Enlightenment. Philosophical fragments, St. Petersburg, (in Russian). Ionin, LG 2012, The rise of minorities, Moscow, 237 p., (in Russian).

Krasavtseva, IN 2017, 'Subculture', Entsiklopediya sotsiologii, viewed 09 December 2017, <https://sociology_encyclopedy.academic.ru/1090/СУБКУЛЬТУРА>, (in Russian).

Krivova, VD (ed.) 2017, 'On the urgent tasks of implementing the state migration policy taking into account the international situation', Analiticheskiy vestnik, no. 55, 79 p., (in Russian).

Migashkina, NB 2008, 'Urban marginal culture: the concept and essence', Munitsipalitet: ekonomika i upravleniye, no. 5, (in Russian).

Park, RE 1928, 'Human migration and the marginal man', American Journal of Sociology, vol. 33, no. 6. https://doi.org/10.1086/214592.

Stonequist, EV 1961, The Marginal Man. A Study in personality and culture conflict, New York.

Zhbankov, MR, Gritsanov, AA, Abushenko, VL, Evelkin, GM, Sokolova, GN \& Tereshchenko, OV (comps.) 2013, 'Marginal culture', Sotsiologiya: entsiklopediya, Minsk, 1312 p., (in Russian). 